\title{
Calcium hydroxide liners: a literature review
}

This article was published in the following Dove Press journal:

Clinical, Cosmetic and Investigational Dentistry

13 July 2017

Number of times this article has been viewed

\section{Naji Ziad Arandi \\ Faculty of Dentistry, The Arab American University, Jenin, Palestine}

Correspondence: Naji Ziad Arandi Faculty of Dentistry, The Arab American University, PO Box 240, Jenin, 13 Zababdeh, Palestine

Tel +97259812 6III

Email Arandi@gmail.com
Objective: This review integrates the literature on cavity liners and current concepts of pulp protection with the aim of establishing a better understanding of the role of calcium hydroxide as a cavity liner.

Materials and methods: A search was conducted through PubMed, MEDLINE, and Ovid for articles with the criteria for the following terms: cavity liners and bases, pulp protection, and calcium hydroxide liners. No specific inclusion or exclusion criteria were applied as to what articles would be included in this review. It was hoped that the extent of the literature reviewed would be as comprehensive as possible.

Conclusion: This review underlines the fact that calcium hydroxide liners should only be used in the deepest spots in the cavity where the remaining dentine thickness is $\leq 0.5 \mathrm{~mm}$. A protective layer of resin-modified glass ionomer should always follow the application of calcium hydroxide liners.

Keywords: liners, calcium hydroxide, pulp protection, pulp therapy, bases

\section{Introduction}

One of the aims of operative dentistry is to preserve the pulp vitality in compromised teeth: one method used for this reason is the use of liners and bases. This involves the placement of protective materials on the unexposed pulp to maintain its health and to stimulate defensive repair by tertiary dentine deposition. The use of liners and bases under restorations has been common practice for many years and continues to be promoted in operative dentistry textbooks as an essential part of restorative procedures. ${ }^{1-3}$ The concepts related to pulp protection have been constantly revisited as the knowledge and understanding of the tooth and dental materials evolve. ${ }^{4-8}$ Traditionally, liners have been used to protect the pulp from the potential toxic effects of restorative materials. Currently, liners are used for their therapeutic effect and/or to seal the dentinal tubules against the ingress of microorganisms or their by-products at the restoration-tooth interface. ${ }^{4,9}$ A variety of dental materials have been introduced as liners to provide pulp tissue protection from irritants related to the restorative procedure. The traditional lining materials include calcium hydroxide, glass ionomer, and resin-modified glass ionomers (RMGIs). Calcium hydroxide has been considered as gold standard for a long time and enjoys the greatest popularity among general dentists. In clinical practice, calcium hydroxide has been reported as liner of choice in patients with deep cavities. ${ }^{10-12}$ This review aims to integrate the literature on calcium hydroxide liners to provide the general dentist with a comprehensive overview that facilitates a better 
understanding of the material and its clinical application in operative dentistry.

\section{Review}

\section{The definition of a "liner"}

The definition of liners itself has been a source of confusion in dental literature. Marzouk et al ${ }^{13}$ defined cavity liners as film-forming materials that carry therapeutic agents, which create their greater film thickness (up to $25 \mu \mathrm{m}$ ) and usually applied to dentine only. Ferracane ${ }^{14}$ described a liner as material that is applied in a thin layer to seal the dentine on the floor and walls of the cavity against the influx of bacteria or irritants from restorative procedures. In 1994, The Journal of Operative Dentistry published a letter submitted by Summit ${ }^{15}$ in which he enlisted cavity liners, varnishes, and resin-bonding agents as subcategories of cavity sealers. He proposed a definition of a cavity liner as a cement or resin coating with minimal thickness (usually $<0.5 \mathrm{~mm}$ ) to achieve a physical barrier to bacteria or a therapeutic effect (a chemical effect which in some way benefits the health of the pulp of the tooth). Later on, McCoy ${ }^{16}$ submitted a letter to The Journal of Operative Dentistry in which he made changes to the original definitions and structure (based on the feedback from Operative Dentistry readers) previously made by Summitt. ${ }^{15}$ McCoy stated that pulp protection materials should be classified into categories based on an increase in thickness and viscosity. Hence, liners were categorized in a separate category and maintained the same definition previously proposed by Summitt. Hilton ${ }^{6}$ defined cavity liners as materials placed with minimal thickness (usually $<0.5 \mathrm{~mm}$ ), which act as cavity sealers and provide expanded beneficial functions, such as fluoride release, adhesion to tooth structure, and/or antibacterial action that promotes the health of the pulp. Ten years later, Hilton ${ }^{17}$ defined cavity liner as cement or resin coating of minimal thickness $(\leq 0.5 \mathrm{~mm})$ that acts as a barrier to bacteria, as well as typically providing a therapeutic effect, such as an antibacterial or pulpal anodyne effect. They added that the placement of the liner is often, but not always, limited to the dentine closest to the pulp. Qualtrough et $\mathrm{l}^{1}$ defined a cavity liner as an aqueous or volatile organic suspension or dispersion of zinc oxide or calcium hydroxide that can be applied to a cavity surface in a relatively thin film. They included glass ionomer and RMGI cements as materials suitable for use as lining materials. Weiner ${ }^{18}$ defined a cavity liner as a thin layer of material $(0.5$ $\mathrm{mm}$ ) placed on the surface of the tooth preparation that, in part, protects the tooth from the restorative material, intraoral fluids, and ultimately from the outside environment but usually do not have sufficient thickness, hardness, or strength to be used alone in a deep cavity. Similarly, Heymann et $\mathrm{al}^{3}$ defined liners as suspensions or dispersions of zinc oxide, calcium hydroxide, or RMGI that can be applied to a tooth surface in a relatively thin film. Anusavice et $\mathrm{al}^{19}$ stated that a cavity liner is a material that is used to coat the bottom of a prepared cavity to protect the pulp; it is applied in a thin layer and usually contains calcium hydroxide or mineral trioxide aggregate (MTA); it also includes certain glass ionomer cements used as intermediate layers between tooth structure and composite restorative material.

It is important to distinguish between two terms "liners" and "suspension liners". Both terms should not be used synonymously. Liners (previously referred to as low-strength bases or cement liners or subbases) are materials placed in deep portions of the cavity preparations that harden when mixed to form a cement layer (100-500 $\mu \mathrm{m})$ usually with minimum strength and low rigidity functioning as a barrier to irritating chemicals and providing therapeutic benefit to the pulp. Suspension liners are set by physical means (drying) and upon the evaporation of the volatile solvent form a relatively thin film $(20-25 \mu \mathrm{m})$ that serves as a protective barrier between dentine and the restorative material and provides some therapeutic effect and provide no mechanical strength, no thermal insulation, and should only be used to line dentine.

\section{Types}

In situations where a liner is indicated, there are several choices of materials. These include calcium hydroxide, RMGI, MTA, and zinc oxide eugenol (ZOE). ZOE liners ${ }^{20}$ (ISO 3107:2004 Type IV) are highly ranked for their antibacterial potential. ${ }^{21} \mathrm{ZOE}$ liners are rarely used or marketed as a cavity liner nowadays; ${ }^{22}$ the updated version of the ISO standards on ZOE and zinc oxide/noneugenol cements (ISO 3107:2011) does not categorize ZOE as a liner. These liners are relatively weak in thin layers, soluble, do not stimulate reparative dentine, and demonstrate high interfacial leakage, for example, Cavitec (Kerr Portland, OR, USA). MTA was also listed by some textbooks as a cavity liner. ${ }^{19}$ However, despite its excellent antibacterial effect, ${ }^{21,23}$ MTA is not recommended as a cavity liner due to its low compressive strength and very slow setting times, which makes it difficult in handling and technique sensitive, especially beneath definitive restorations. ${ }^{24}$ RMGI liners are formulated from fluoroaluminosilicate glasses, photoinitiators, polyacrylic acid, water, and a water-soluble methacrylate monomer, such as hydroxyethyl methacrylate, which may or may not be integrated onto the 
polyacrylic acid. ${ }^{25}$ They were developed in an attempt to improve mechanical properties, decrease setting time, and attenuate moisture sensitivity of conventional glass ionomers. RMGI liners provide adequate sealing and protection to the dental pulp due, in part, to the chemical adhesion to dental substrates combined with their ability to release fluoride, ${ }^{22}$ for example, Vitrebond (3M, ESPE) and GC Fuji II LC (GC Corporation, Tokyo, Japan). Of all these materials, calcium hydroxide was initially proposed by Hermann ${ }^{59}$ in 1930 as a "remineralizing agent" in direct pulp capping, and calcium liners probably enjoy the greatest popularity among general dentists and have been considered to be the gold standard by which other vital pulp modalities are measured. ${ }^{9}$

There are a variety of views and approaches when it comes to using cavity liners. ${ }^{11,26-28}$ A 1995 survey on teaching the use of bases and liners concluded that dental schools in North America do not agree on which liner material to use and when to use it. In the mid-1990s, for a deep cavity that was to be restored with an amalgam, $46 \%$ of the 52 schools that replied advocated the use of a glass ionomer as a liner followed by $25 \%$ in favor of calcium hydroxide. The survey considered cavities with $1 \mathrm{~mm}$ remaining dentine thickness (RDT) as deep cavities since there were no strict guidelines for defining a deep cavity in the literature at that time. ${ }^{26}$ Likewise, in a more recent survey on liners taught by dental schools in North America, there was no agreement on a standard pulp protection protocol. Thirty-eight percent of the 39 dental schools involved in the survey reported that calcium hydroxide liners were taught for deep preparations with amalgam restoration followed by $30.8 \%$ that taught glass ionomer liners. The survey also reported that for composite restorations in a deep cavities, the liners most frequently used were glass ionomers $(35.9 \%)$ followed by calcium hydroxide (28.2\%). However, the 1995 survey did not offer scenarios that included composite restorations. ${ }^{27}$ Another study investigated the practice of dental pulp protection methods among 500 final year students, young clinicians, and interns in various teaching institutions in Pakistan and concluded that the contemporary protocols for pulp protections are not being followed by the respondents in the institutions that participated in the survey, for example, $\sim 89 \%$ of the respondents did not consider RDT essential while $82 \%$ of them considered using calcium hydroxide liners essential under all direct restorations. ${ }^{28}$

\section{Conventional calcium hydroxide liners}

Calcium hydroxide for the purpose of pulp protection is available in various forms, such as in aqueous suspensions or as cements, liners, or filled risens. Calcium hydroxide aqueous suspensions are suspensions of calcium hydroxide in water. After application, the solvent evaporates, leaving behind (as a liner) a layer of calcium hydroxide, for example, Pulpdent (Pulpdent, Brookline, MA, USA). Calcium hydroxide liners, however, are a combination of calcium hydroxide with a varnish to modify the viscosity and to improve handling, ${ }^{20,29,30}$ for example, Hydroxline (George Taub, Jersey City, NJ, USA). Calcium hydroxide cements are paste/paste systems. One paste contains calcium hydroxide and the other contains salicylate. Salicylate is a weak acid that is chemically similar to eugenol and reacts with the calcium hydroxide. ${ }^{29}$ The acid-base reaction between calcium hydroxide and a salicylate is responsible for setting, the reaction forms an amorphous calcium disalicylate. ${ }^{31}$ This form of calcium hydroxide materials fit into what was previously described as low-strength bases, ${ }^{32}$ for example, Dycal (Dentsply, Milford, DE, USA) and Life (Kerr, Portland, OR, USA).

Ideally, liners should possess antibacterial properties. The ability of these liners to prevent bacterial growth under restorations is of great importance as the numbers of bacteria in a cavity decrease the extent of pulpal inflammation is reduced. Calcium hydroxide liners are reported to display antibacterial properties. ${ }^{33}$ The antimicrobial properties of calcium hydroxide come from its dissociation into calcium and hydroxyl ions. The hydroxyl ions create an alkaline $\mathrm{pH}$ that is unfavorable for remaining bacteria in the cavity. Hydroxyl ions are highly oxidant free radicals that show high reactivity. ${ }^{34}$ The antimicrobial action of hydroxyl ions on microorganisms can be explained by their influence on growth, structure, metabolism, and bacterial cell division. ${ }^{23,30}$ The antibacterial properties of calcium hydroxide were reported inferior to RMGI liners ${ }^{35,36}$ and stronger than other materials commonly used for lining (especially the conventional glass ionomer cement). Calcium hydroxide liners were also reported to reduce bacterial numbers much more effectively than only sealing the cavity. ${ }^{21}$ However, calcium hydroxide liners show reduced antibacterial activity overtime. ${ }^{37}$

Calcium hydroxide has significant drawbacks; the low elastic modulus and low compressive strength of calcium hydroxide cavity liners restricts their usage to thin layers in specific areas, which is not critical to the support of restorations. ${ }^{31,38}$ Calcium hydroxide liners have low thermal conductivity, but they are usually not used in thick enough layers $(\leq 0.5 \mathrm{~mm})$ to provide thermal protection; ${ }^{20}$ therefore, thermal protection should be provided with a separate base. Hence, it is recommended that they should be only applied over the smallest area that would suffice to aid in 
pulp therapy. ${ }^{2}$ Calcium hydroxide liners must not be left on the margin of the prepared cavity or the margin will not be properly sealed because the liner is soluble in water. ${ }^{19}$ It has high solubility and water sorption, ${ }^{39}$ which may result in softening of the liner and in material loss under poorly sealed tooth-restoration interface where the oral fluids can penetrate through and partially or totally dissolve this pulp-protecting material. ${ }^{9}$ This was previously described in the literature as the "Disappearing Dycal" syndrome. ${ }^{7}$ Calcium hydroxide liners should not be acid etched as it might be softened and smeared over the walls of the cavity, which may contaminate acid-etched enamel and produce an inferior bond. ${ }^{40,41}$ Phillips et $\mathrm{al}^{40}$ reported that the solubility of calcium hydroxide (paste/paste) liners in phosphoric acid (37\%) varies markedly among brands and it is dependent on the commercial preparation. The same study also reported that solubility of calcium hydroxide might be sensitive increase in base/catalyst ratio.

Operative dentistry books recommend a calcium hydroxide liner if the excavation extends close to the pulpal tissue. ${ }^{3}$ Current concepts on pulp protection define "close to the pulp" as the case where the RDT between the floor of the cavity preparation and the pulp is $\leq 0.5 \mathrm{~mm} .{ }^{42}$ Calcium hydroxide liners are reported to mediate underlying odontoblasts survival when the RDT is $\leq 0.5 \mathrm{~mm} .{ }^{42,43}$ Maintaining the health and vitality of the odontoblast cell layer is important as it is responsible for the capacity of the dental pulp to protect itself by the deposition of tertiary dentine secreted by primary odontoblasts. ${ }^{44}$ The influx of calcium ions from the dissociated material toward the pulp triggers the recruitment and proliferation of undifferentiated cells from the pulp and activates stem cells. ${ }^{45}$ Calcium hydroxide has the ability to slightly demineralize dentine, and in turn release transforming growth factor- $\beta 1$ from the matrix that signals tertiary dentinogenesis that is responsible for repair in dentine pulp complex and, in turn, supports the success of much of restorative dentistry. ${ }^{46-48}$ About et $\mathrm{al}^{49}$ reported that calcium hydroxide maintained the highest number of odontoblasts (compared to zinc polycarboxylate, ZOE, and RMGI) beneath restored cavities when the RDT is $<0.5 \mathrm{~mm}$. Murray et $\mathrm{al}^{42,50}$ reported that in cases with a cavity RDT is $<0.5 \mathrm{~mm}$ and no pulp exposure is present; calcium hydroxide liners displayed the greatest area of reactionary dentine deposition when compared with other pulp-protecting materials, such as RMGI, ZOE, and zinc polycarboxylate. In cases where the RDT is between 0.5 and $1.5 \mathrm{~mm}$, calcium hydroxide liners are not necessary. ${ }^{4}$ Instead, an RMGI liner should be used to replace the lost dentine and to provide volumetric reduction of composite resins to reduce the drawbacks of polymerization shrinkage of dental composites. RMGI provides adequate sealing and protection to the dental pulp due, in part, to the chemical adhesion to dental substrates, fluoride release, decreased solubility, and superior mechanical properties. ${ }^{4,31}$ However, they should not be used in deep cavities where the RDT is $\leq 0.5 \mathrm{~mm}$ in order to limit pulp injury. ${ }^{42}$

The current protocols for pulp protection impose a protective RMGI base wherever calcium hydroxide liners are indicated to compensate for the drawbacks of calcium hydroxide liners, that is, if microleakage occurs at the interface between the restoration and the tooth, the RMGI will act as an insoluble barrier against bacterial penetration into the deeper portions of the cavity preparation. Calcium hydroxide liners do not adhere to dentine or resin-based restorative materials. Hence, they provide a poor seal. The adaptation between dentine and Dycal and also between Dycal and Vitrebond (3M ESPE) was evaluated under scanning electron microscope (SEM), marked gaps were seen between Dycal and dentine, on one hand, and between Dycal and Vitrebond, on the other hand. The study attributed the gaps to the lack of adhesion of Dycal to Vitrabond and dentine as well. ${ }^{51}$ Similar results were also reported by another SEM study by Chen et $\mathrm{al},{ }^{52}$ which concluded that there was a big gap between Dycal and the overlying Vitrebond. Therefore, enough enamel and dentine should be left exposed for adhesion of the overlying protective RMGI layer since studies report good adaptation and bonding between dentine and Vitrebond. ${ }^{4,51,52}$

Due to their alkaline nature, they also serve as a protective barrier against irritants from other restorative materials; using calcium hydroxide liners under RMGI is the best way of avoiding needles odontoblast injury that might result from applying RMGI in deep cavities. ${ }^{53}$ Calcium hydroxide liners are also recommended as a protective layer "subbase" beneath a ZOE temporary restoration..$^{54}$ Similarly, in deep cavities with minimal remaining dentine covering the pulp, calcium hydroxide liners are recommended as a protective layer under zinc phosphate cements - to help reduce the effects of the initial low $\mathrm{pH}$ (4.2 at 3 minutes). ${ }^{55}$

\section{Light-cured calcium hydroxide liners}

A single component liner that contains calcium hydroxide and is polymerized by visible light was introduced in 1988 to help address the limitations of the chemical cure calcium hydroxide; that is, they set on command, improved strength, essentially no solubility in acid, and minimal solubility in water. ${ }^{56} \mathrm{~A}$ visible light-cured (VLC) calcium hydroxide liner consists of calcium hydroxide and barium sulfate dispersed in a urethane dimethacrylate resin containing initiators and 
accelerators activated by visible light. ${ }^{31}$ The fact that this material is based on polymeric resins allows for bonding between it and the overlaying composite restoration. ${ }^{39,56}$ It should be noted that if subsequent use of a dentine-bonding agent is desired, the VLC liner should only be applied on the deepest ( $<1 \mathrm{~mm}$ remaining) dentine, leaving the rest of the cavity surface free for bonding. VLC calcium hydroxide liners are mainly indicated for indirect pulp capping and as a cavity liner under all types of restoratives, for example, Calcimol (Voco GmbH, Cuxhaven, Germany) and Lime-lite (Pulpdent Corporation, Watertown, MA, USA).

There is little proof that VLC calcium hydroxide liners actually release calcium ions necessary for reactionary dentine formation. A study by Gandolfi et $\mathrm{al}^{45}$ compared the release of calcium ions by Dycal, Life, and Lime-Lite and found that the amount of calcium released by Lime-Lite was negligible compared to that released by the chemical set formulas (Dycal and Life). There is little proof of considerable antibacterial effect of the VLC calcium hydroxide liners; the vehicle component of these light-cured products may prevent or significantly reduce any antimicrobial effects associated with the chemical cure products. McComb and Ericson ${ }^{33}$ reported significant difference in the antibacterial effect between a conventional two-paste calcium hydroxide cement (Advanced Formula II Dycal, LD Caulk Co/ Dentsply) and the visible-light-cured liner containing calcium hydroxide (Prisma VLC Dycal, LD Caulk Co/ Dentsply). They reported no antibacterial activity of the light-cured calcium hydroxide liner (Prisma VLC Dycal) and concluded that this material was inert. Coogan and Creaven ${ }^{37}$ reported that the antibacterial action of Prisma VLC Dycal is limited and its antibacterial properties were significantly less than that displayed by the chemically cured Dycal. Similarly, Poggio et $\mathrm{al}^{23}$ studied the antimicrobial effect of Calcimol LC and Dycal using an agar diffusion test and found Dycal to have a significantly higher antimicrobial activity compared to the Calcimol LC. Staehle et $\mathrm{al}^{30}$ studied the alkalizing properties of calcium hydroxide compounds and reported that the degree of ion release, combined with definite antimicrobial properties for light-cured calcium hydroxide is lower than that of the conventional paste/paste forms of calcium hydroxide. However, Lado and Stanley ${ }^{57}$ compared the antimicrobial activity of light-cured calcium hydroxide pulp capping products to self-cure products by an in vitro microbial assay and reported that all the products tested resulted in similar size zones of inhibition $(P<0.10)$. They concluded that the VLC products are equally effective as standard self-curing, pulp capping products in inhibiting the growth of organisms commonly found at the base of a cavity preparation. Yalcin et $\mathrm{al}^{58}$ investigated the antibacterial effects of Dycal and the light-cured calcium hydroxide liner (Calcimol LC) using the direct contact test. The authors reported that both of these materials showed no antibacterial activity.

\section{Conclusion}

Calcium hydroxide liners should not be overused. Calcium hydroxide liners are used for its bioinductive and antimicrobial activity. It should be only used in the deepest spots in the cavity where the RDT is $\leq 0.5 \mathrm{~mm}$. The placement of calcium hydroxide should be followed by a layer of RMGI to protect it from its drawbacks.

\section{Disclosure}

The author reports no conflicts of interest in this work.

\section{References}

1. Qualtrough AJE, Satterthwaite JD, Morrow LA, Brunton PA. Principles of Operative Dentistry. 2005. Avilable from: http://www.lmdc.edu.pk/ downloads/principalsofoperativedentistry.pdf. Accessed April 9, 2017.

2. Hilton TJ, Ferracane JL, Broome JC, editors. Summitt's Fundamentals of Operative Dentistry: A Contemporary Approach. 4th ed. Hanover Park: Quintessence Publishing Co; 2013.

3. Heymann H, Swift EJ, Ritter AV, Sturdevant CM, editors. Sturdevant's Art and Science of Operative Dentistry. 6th ed. St Louis: Elsevier/ Mosby; 2013.

4. Ritter AV, Swift Jr EJ. Current restorative concepts of pulp protection. Endod Top. 2003;5(1):41-48.

5. Leinfelder KF. Changing restorative traditions: the use of bases and liners. J Am Dent Assoc. 1994;125(1):65-67.

6. Hilton TJ. Cavity sealers, liners, and bases: current philosophies and indications for use. Oper Dent. 1996;21(4):134-146.

7. Tyas MJ. Pulp protection under restorations-Do you need a liner? Aust Endod J. 1998;24(3):104-108.

8. Strassler HE. New concepts with bases and liners. J Esthet Dent. 1992;4(4):140-141.

9. Brännström M. Communication between the oral cavity and the dental pulp associated with restorative treatment. Oper Dent. 1984;9(2):57-68.

10. Chisini LA, Conde MC, Correa MB, et al. Vital pulp therapies in clinical practice: findings from a survey with dentist in Southern Brazil. Braz Dent J. 2015;26(6):566-571.

11. Aljanakh M, Mirza AJ, Siddiqui AA, Al-Mansour M, Asad M. Do dentists in Ha'il region follow contemporary pulp protection protocols? A Saudi based tudy. Int J Dent Sci Res. 2016;4(4):68-71.

12. Schwendicke F, Meyer-Lueckel H, Dörfer C, Paris S. Attitudes and behaviour regarding deep dentin caries removal: a survey among German dentists. Caries Res. 2013;47(6):566-573.

13. Marzouk MA, Simonton AL, Gross RD, Cargas HJ, editors. Operative Dentistry: Modern Theory and Practice. 1st ed. Ishiyaku:EuroAmerica; 1985.

14. Ferracane JL. Materials in Dentistry: Principles and Applications. 2nd ed. Philadelphia: Lippincott Williams \& Wilkins; 2001.

15. Summitt JB. On bases, liners, and varnishes. Oper Dent. 1994;19(1):1-40.

16. McCoy RB. On liners, bases, and varnishes update. Opera. 1995; 20(5):216.

17. Hilton TJ. Sealers, liners, and bases. J Esthet Restor Dent. 2016;28(3): 141-143.

18. Weiner R. Liners, bases, and cements: an in-depth review, part 1. Dent Today. 2008;27(5):72, 74, 76; quiz 78. 
19. Anusavice KJ, Phillips RW, Shen C, Rawls HR. Phillips' Science of Dental Materials. 12th ed. Philadelphia: WB Saunders; 2012.

20. Powers JM, Wataha JC, Chen YW. Dental Materials: Foundations and Applications. Available from: https://www.libreriauni verso.it/articolo/78043/9780323316378-dental-materials-propertiesmanipulation-powers-wataha-elsevier-mosby. Accessed April 9, 2017.

21. Schwendicke F, Tu YK, Hsu LY, Göstemeyer G. Antibacterial effects of cavity lining: a systematic review and network meta-analysis. $J$ Dent. 2015;43(11):1298-1307.

22. Weiner R. Liners and bases in general dentistry. Aust Dent J. 2011;56:11-22.

23. Poggio C, Arciola CR, Beltrami R, et al. Cytocompatibility and antibacterial properties of capping materials. Sci World J. 2014;2014:181945.

24. Parirokh M, Torabinejad M. Mineral trioxide aggregate: a comprehensive literature review-Part I: chemical, physical, and antibacterial properties. J Endod. 2010;36(1):16-27.

25. Berzins DW, Abey S, Costache MC, Wilkie CA, Roberts HW. Resinmodified glass-ionomer setting reaction competition. $J$ Dent Res. 2010;89(1):82-86.

26. Weiner RS, Weiner LK, Kugel G. Teaching the use of bases and liners: a survey of North American dental schools. J Am Dent Assoc. 1996;127(11):1640-1645.

27. Weiner R. Teaching the use of liners, bases, and cements: a 10-year follow-up survey of North American Dental Schools. Dent Today. 2006;25(6):74, 76, 78-9; quiz 79.

28. Javaid A, Asad M, Khan S, Berkth M. Practice of dental pulp protection methods among various teaching institutions in Pakistan. $J$ Pakistan Dent Assoc. 2016;25(1):16-20.

29. Gladwin MA, Bagby MD. Clinical Aspects of Dental Materials: Theory, Practice, and Cases. 3rd ed. Philadelphia: Lippincott Williams \& Wilkins; 2009.

30. Staehle HJ, Pioch T, Hoppe W. The alkalizing properties of calcium hydroxide compounds. Endod Dent Traumatol. 1989;5(3):147-152.

31. Sakaguchi RL, Powers JM. Craig's Restorative Dental Materials. Philadephia, PA: Elsevier/Mosby; 2012.

32. Hatrick CD, Eakle WS, Bird WF. Dental Materials: Clinical Applications for Dental Assistants and Dental Hygienists. 3rd ed. St Louis: Elsevier/Saunders; 2014.

33. McComb D, Ericson D. Antimicrobial action of new, proprietary lining cements. J Dent Res. 1987;66(5):1025-1028.

34. Estrela C, Holland R. Calcium hydroxide: study based on scientific evidences. J Appl Oral Sci. 2003;11(4):269-282.

35. Coogan MM, Creaven PJ. Antibacterial properties of eight dental cements. Int Endod J. 1993;26(6):355-361.

36. Eli I, Cooper Y, Ben-Amar A, Weiss E. Antibacterial activity of three dental liners. J Prosthodont. 1995;4(3):178-182.

37. Coogan MM, Creaven PJ. Antibacterial properties of eight dental cements. Int Endod J. 1993;26(6):355-361.

38. Tam LE, Pulver E, McComb D, Smith DC. Physical properties of calcium hydroxide and glass-ionomer base and lining materials. Dent Mater. 1989;5(3):145-149.

39. Francisconi LF, de Freitas AP, Scaffa PMC, Mondelli RFL, Francisconi PAS. Water sorption and solubility of different calcium hydroxide cements. J Appl Oral Sci. 17(5):427-431.
40. Phillips RW, Crim G, Swartz ML, Clark HE. Resistance of calcium hydroxide preparations to solubility in phosphoric acid. J Prosthet Dent. 1984;52(3):358-360.

41. El-Araby A, Al-Jabab A. The influence of some dentin primers on calcium hydroxide lining cement. J Contemp Dent Pract. 2005;6(2):1-9.

42. Murray PE, Smith AJ. Saving pulps-a biological basis. An overview. Prim Dent Care. 2002;9(1):21-26.

43. Murray PE, Smith AJ, Windsor LJ, Mjör IA. Remaining dentine thickness and human pulp responses. Int Endod J. 2003;36(1):33-43.

44. Murray PE, Windsor LJ, Smyth TW, Hafez AA, Cox CF. Analysis of pulpal reactions to restorative procedures, materials, pulp capping, and future therapies. Crit Rev Oral Biol Med. 2002;13(6):509-520.

45. Gandolfi MG, Siboni F, Botero T, Bossù M, Riccitiello F, Prati C. Calcium silicate and calcium hydroxide materials for pulp capping: biointeractivity, porosity, solubility and bioactivity of current formulations. J Appl Biomater Funct Mater. 2015;13(1):43-60.

46. Smith AJ, Murray PE, Lumley PJ. Preserving the vital pulp in operative dentistry: I. A biological approach. Dent Update. 2002;29(2):64-69.

47. Graham L, Cooper PR, Cassidy N, Nor JE, Sloan AJ, Smith AJ. The effect of calcium hydroxide on solubilisation of bio-active dentine matrix components. Biomaterials. 2006;27(14):2865-2873.

48. Ferracane JL, Cooper PR, Smith AJ. Can interaction of materials with the dentin-pulp complex contribute to dentin regeneration? Odontology. 2010;98(1):2-14.

49. About I, Murray PE, Franquin JC, Remusat M, Smith AJ. The effect of cavity restoration variables on odontoblast cell numbers and dental repair. J Dent. 2001;29(2):109-117.

50. Murray PE, Lumley PJ, Smith AJ. Preserving the vital pulp in operative dentistry: 2. Guidelines for successful restoration of unexposed dentinal lesions. Dent Update. 2002;29(3):127-134

51. John NK, Kv M, Joseph B, Kuruvilla A, Faizal N, Babu BS. A comparative evaluation of the internal adaptation of various lining materials to dentin under light cure composite restorations: a scanning electron microscope study. J Int Oral Health. 2017;9(1):6-11.

52. Chen L, Cannon M, Suh BI. SEM and bond strength evaluation of adaptation between liners-composites. Dent Mater. 2015;31(Suppl 1):e7-e8.

53. Murray PE, About I, Lumley PJ, Franquin JC, Remusat M, Smith AJ. Cavity remaining dentin thickness and pulpal activity. Am J Dent. 2002;15(1):41-46.

54. O'Brien WJ. Dental Materials and Their Selection. 3rd ed. Hanover Park: Quintessence Publishing Co; 2002.

55. Weiner R. Liners, bases, and cements in clinical dentistry. A review and update. Dent Today. 2003;22(8):88-93.

56. Stanley HR, Pameijer CH. Pulp capping with a new visible-light-curing calcium hydroxide composition (Prisma VLC Dycal). Oper Dent. 1985;10(4):156-163.

57. Lado EA, Stanley HR. An in vitro study of bacterial inhibition by VLC calcium hydroxide pulp cap compounds. Pediatr Dent. 1987;9(4):292-294.

58. Yalcin M, Arslan U, Dundar A. Evaluation of antibacterial effects of pulp capping agents with direct contact test method. Eur J Dent. 2014;8(1):95-99.

59. Hermann BW. Dentinobliteration der wuérzelkanaélen nach behandlung mit calzium. Zahnarztl Rundsch. 1930;21:888-899. German.
Clinical, Cosmetic and Investigational Dentistry

\section{Publish your work in this journal}

Clinical, Cosmetic and Investigational Dentistry is an international, peer-reviewed, open access, online journal focusing on the latest clinical and experimental research in dentistry with specific emphasis on cosmetic interventions. Innovative developments in dental materials, techniques and devices that improve outcomes and patient satisfac-

\section{Dovepress}

tion and preference will be highlighted. The manuscript management system is completely online and includes a very quick and fair peerreview system, which is all easy to use. Visit http://www.dovepress. $\mathrm{com} /$ testimonials.php to read real quotes from published authors. 